\title{
EWA STRAŚ
}

Uniwersytet Śląski

Katowice, Polska

\section{Мечта / marzenie как компонент устойчивых словосочетаний русского и польского речевого узуса}

Мечта как многоаспектное проявление внутренней жизни представляет собой интерес для различных наук, исследующих процессы ее зарождения, протекания во времени, движущей силы, а также предоставляемой человеку поддержки. Проблема эта обсуждается в психологии, эпистемологии, философии, социологии. И это лишь некоторые из возможных областей изучения названного явления. Естественным образом она вызывает интерес и у языковедов. Так, например, С.А. Сергеев описывает структуру соответствующего концепта (Сергеев 2006: 207), Е.Б. Никифорова выявляет изменения в составе синонимов слова мечта (Никифорова 2006: 204), А.А. Иванова решает вопросы, связанные с двуязычными сопоставлениями фразеологических единиц с данным словом как компонентом (Иванова 2011: 60).

Названные публикации послужили стимулом для разработки заявленной темы. Согласно полученным представлениям, мечта / marzenie является единицей относительно ограниченной с точки зрения сочетаемости, образующей словосочетания, устойчивые по своему характеру, т.е. воспроизводимые в готовом виде. Традиционно их принято называть фразеологизированными выражениями. По отношению к ним употребляется также термин коллокации (Борисова 1995: 11). Это сочетания слов, в составе которых выбор одного компонента определяется смыслом передаваемого сообщения, в то время как выбор другого обусловлен не только его характером, но уже выбранным перед тем компонентом. Тем самым, совместное появление сочетаемых слов задается семантическими факторами. Кроме того, как пишет М.В. Влавацкая, «Понятие коллокащии стало также применяться в корпусной лингвисти- 
ке, где оно приобрело более упрощённое [...] значение. Акцент ставится на частоте совместной встречаемости, поэтому коллокации в корпусной лингвистике могут быть определены как статистически устойчивые словосочетания» (Влавацкая 2011: 37). В связи с чем, может быть, более подходящим для таких единиц и было бы определение статистически устойчивые словосочетания?

Устойчивость подобного рода не следует все же смешивать с понятием устойчивости во фразеологии, обязательной, наравне с воспроизводимостью и идиоматичностью, для ФЕ (см., напр., Жеребило 2010). Статистическая устойчивость при этом, как можно это себе представить, более близка воспроизводимости. Сосредоточим по этой причине внимание для начала на ней. В ходе анализа мы постараемся сопоставить воспроизводимые выражения русского и польского языков, включающие в свой состав существительное мечта / marzenie, используя с этой целью толковые и двуязычные словари, словарь сочетаемости слов (УСС), словарь «хорошего стиля» (SDS), а также данные национальных корпусов русского и польского языков в количестве, соответственно, 4314 и 3352 словоупотреблений. Особое внимание будет уделено фразеологическому словарю С. Скорупки (SFJP), как наиболее полному лексикографическому источнику в интересующем нас отношении, включающему, помимо традиционно определяемых фразеологических единиц (ФЕ), выражения, не обладающие всеми типичными для ФЕ чертами. Собранный языковой материал будет обсуждаться с точки зрения его воспроизводимости и частотности употребления, оставляя в поле зрения ФЕ и словосочетания фразеологизированные (коллокации), на фоне словосочетаний, сближающихся со свободными. Сопоставление сочетаемости слов мечта и marzenie будет производиться для выбранных языков параллельно.

Мечта занимает важное место в сознании, однако в виду нечетких границ понятия, как слово, она фиксируется словарями с учетом различных оттенков значения. В наиболее сжатом виде мечта толкуется следующим образом: 1. 'нечто, созданное воображением, мысленно представляемое'; 2. 'предмет желаний, стремлений'; 3. (в значении сказуемого) 'о чем-н. очень хорошем' (разг. шутл.) (ОШ). В польском эквивалентное слово marzenie получает, в частности, следующее словарное определение: 1. 'przedmiot pragnień; to, czego pragniemy i co zamierzamy mieć lub osiągnąć, ale czego realizacja nie zawsze jest łatwa czy możliwa'; 2. 'coś doskonałego; coś co zachwyca kogoś swoją doskonałością lub pięknem' (WSJP). При сравнении с русским можно отметить большую прагматичность польского представления (опираясь при этом на приведенные словари).

Говоря о воспроизводимости словосочетаний, следовало бы обратить внимание, прежде всего, на то, как они отображаются в лексикографических источниках. Словосочетание идиоматическое, в готовом виде воспроизводимое, устойчивое и семантически целостное, получая статус ФЕ, должно 
отражаться фразеологическим словарем. Хотя подобные словари содержат нередко и коллокации. Связано это, в первую очередь, с тем, что границы между ФЕ, коллокациями, а также нередко свободными словосочетаниями не всегда очевидны, неоднозначны, неточны, а поэтому, устанавливаясь с трудом, вызывают вполне объяснимые колебания.

Поскольку мечта (мечтание), как и marzenie, имеют формы, соотносительные по числу, обсуждение начнем с формы множественного числа. В русском языке таковыми будут предел мечтаний, достичь предела мечтаний, распрощаться с мечтами (WSF). Исходя из этих примеров трудно сказать, что мечты образуют какой-то свой собственный ограниченный мир, хотя предел мечтаний предполагает, хотя бы косвенно, некую определяющую их границу. Такие примеры из словарных статей, как стремиться в мечтах (к чему?), уноситься в мечтах, предаваться мечтам, обладая образностью, свойственной как ФЕ, так и коллокациям, как следствие из нее, содержат некое представление о том, что есть некая область, к которой и следует относить мечты.

Существительное marzenie в форме множественного числа фиксируется словарями в таких фразеологических сочетаниях: puścić, popuścić wodze / cugle marzeniom (SFPWN), а также drużyna marzeń (WSJP). В свою очередь, единицы из польско-русского фразеологического словаря (WSF) pożegnać się z marzeniami и szczyt marzeń, być u szczytu marzeń снабжаются комментарием о средней и низкой семантической спаянности компонентов. Те же самые выражения содержатся также в SFJP, включающем словосочетания bujać (żyć) $w$ krainie (w świecie) marzeń, oddawać się marzeniom, karmić się marzeniami, stanać u celu swych marzeń, oblekać marzenia w czyny, unosić się na skrzydłach marzeń; roić marzenia, rozproszyć marzenia, rozwiać marzenia, snuć marzenia, ocknąć się z marzeń, przebudzić się z marzeń, pograżyć się w marzeniach, zatopić się $w$ marzeniach. На основании все той же заключенной в них образности можно себе представить своеобразный мир мечтаний - окрыленных, легких и улетучивающихся словно туман. Если добавить к этому единицы из WSF, то этот мир обогатится воображениями о движении вверх до предельной вершины. Противоположно действуют выражения, лишенные образности realizować marzenia, mieć marzenia, spetniać marzenia (SDS). Два последних словосочетания отмечаются также в SFJP.

ФЕ со словом мечта (мечтание) в единственном числе, фиксируемых русскоязычными словарями, в целом немного. К ним относятся голубая мечта, розовая мечта и устаревшее весеннее мечтание, отмечаемые историко-этимологическим справочником (СРФ). Для польского это senne marzenie, zniknąć / minąć jak senne marzenie и marzenie ściętej głowy (SFPWN). Перечисленные словосочетания, скорее всего, коллокации, хотя в последнем примере с большей силой себя проявляют признаки фразеологизма. 
Говоря о коллокациях, необходимо иметь в виду, прежде всего, характерную для них открытость состава, способного к пополнению новыми воспроизводимыми словосочетаниями, что может затем найти свое отражение в словарях. В связи с динамикой речи важным источником языковедческих уточнений можно считать материалы национальных корпусов, представляющих собой одновременно и замкнутый, и пополняемый ресурс. Как было ранее сказано, особый интерес для исследователей языка составляют в указанном отношении так называемые статистически устойчивые словосочетания. Встречаться и повторяться могут при этом, что вполне очевидно, ФЕ, коллокации и свободные словосочетания. Попытки установить характер и меру спаянности компонентов, проводившиеся с использованием статистических методов, опирались на ассоциациях (Захаров, Хохлова 2010: 138). Их результаты оказались сходными с данными словарей: «данные об устойчивой сочетаемости, приведенные в словарях, совпадают с данными, полученными на основе мер ассоциации» (Захаров, Хохлова 2010: 141). На основании приводимых в этом исследовании примеров можно лишний раз убедиться в том, что ФЕ в статистическом отношении занимают частотно высокое место. Подобного рода исследования проводились и продолжают проводиться, поскольку корпусная лингвистика и развивается, и совершенствуется. Тем не менее, они подтверждают, что и традиционное изучение лексического состава языка давало свои положительные результаты. В связи с чем постараемся, используя свою интуицию, при поддержке со стороны статистических данных корпусов и поисковой системы Google, определить степень устойчивости некоторых коллокаций ${ }^{1}$.

Статистически устойчивые словосочетания можно обнаружить в разных источниках и, прежде всего, в словарях сочетаемости. Для польского языка таким словарем может быть SDS, для русского, в частности, словарь сочетаемости слов (УСС). Способ построения словарной статьи в этом последнем, равно как и порядок, принятый в других лексикографических источниках, будет передавать формальную схему предпринятого нами исследования. Та, в свою очередь, ляжет в основу далее представляемых моделей, отображающих формальную сторону лексико-семантических основ коллокаций, в ряде случаев подтверждаемых примерами употребления.

Мечта создается воображением и существует в сознании. Человек выступает при этом как обладатель мечты, что и находит свое отражение в посессивной конструкции вида мечта / marzenie $+\mathrm{S}_{\mathrm{G}}$ : мечта идиота (19), поэma (18)...; marzenie czlowieka (9); mieszkańców (5) ... Построенные подобным образом выражения способны распространяться местоимениями (любой, каж$\partial b i u ̈ ; ~ в е c b / k a z ̇ d y$, wszystek) в форме родительного падежа, с учетом категории

${ }^{1}$ Отбор коллокаций в польском языке производился с использованием данных, помещенных в части Корпуса: www.nkjp.uni.lodz.pl/collocations.jsp (доступ: 24.04.2016). 
рода и числа. Местоимения дополняют значение компонента, выступающего в родительном падеже. Другая модель (мечта / marzenie $+\mathrm{S}_{\mathrm{G}}$ ), структурно такая же, предполагая в качестве реализации для $\mathrm{S}_{\mathrm{G}}$ абстрактное либо собирательное существительное, более ограниченная по количеству словоупотреблений, не может рассматриваться как посессивная, ср.: мечта детства (28), человечества (13), жсизни (8) ... и marzenie życia (10), dzieciństwa (5), ludzkości $(4)^{2} \ldots$ Подобным единицам свойственна также бо́льшая степень смысловой ограниченности, чем для мечта / marzenie кого? (чья?), что позволяет увидеть в них черты коллокаций, сближающихся с ФЕ.

Определив обладателя, обратимся к предмету мечты. Им может быть объект реальной или нереальной действительности, что выражает себя в конструкции мечта / marzenie + о $+\mathrm{S}_{\mathrm{L}}$. . . мечта о море (3) ...; ... о рае (3) и т.п. В польском языке та же модель подтверждается такими примерами: ... marzenie o kobiecie (6), o życiu (4) ... и т.п. Помимо формальной зависимости в виде предлога $o$, для присоединяемых существительных других ограничений не наблюдается. Мечтать можно о чем угодно, по этой причине семантической обусловленности обнаружить не удается.

Существительное мечта конкретизирует также свое значение, сочетаясь с различными прилагательными. Атрибутивно-субстантивная модель Adj + мечта / marzenie не предполагает ограничений для выражения качеств мечты. Тем не менее, многие из прилагательных повторяются в составе рассмотренных словосочетаний относительно часто: заветная (178), давняя (146), главная (69), детская (56), большая (45), несбыточная (40), вековая (12), сбывшаяся (10), единственная (10), сокровенная (10), маленькая (3). То же самое можно отметить и для польского языка, особого внимания при этом заслуживают прилагательные: największe (123), wielkie (63), spetnione (39), niespetnione (22), odwieczne (17), ciche (17), zyciowe (13), sportowe (11), najskrytsze (10), jedyne (8) ${ }^{3}$ и т.п. Большинство из них находит свое отражение в словаре SDS, составленном по данным NKJP. Как можно заметить, характеристики, сопровождающие мечту, относятся к представлениям о времени ее появления или существования, величине либо мере и степени проявления. Как представляется, семантически более тесно связаны с существительными мечта / marzenie прилагательные с относительно высокой частотностью употребления. Осознаваемая в них семантическая спаянность позволяет их относить к коллокациям.

Иногда положительные черты, обнаруживаемые в объекте реальной действительности, способствуют тому, что он сопоставляется с мечтой, а так-

2 Примеры даются в порядке частотности употребления в НКРЯг и NKJP. Цифры в круглых скобках указывают на количество словоупотреблений.

${ }^{3}$ Согласно данным поисковой системы google.ru, равно как и google.pl порядок приводимых примеров другой. 
же мечтой называется, что следует признать проявлением положительной оценки: „Не мужчина - мечта; Высокий, красивый - мечта, а не парень; [...] словом, не женщина, а мечта..." (НКРЯг). То же самое можно сказать и о слове marzenie для польского материала: „Syn marzenie, ale niestety spotkat mnie $i$ się zakochat; [...] no facet marzenie i przystojny...; drzwi się otworzyly $i$ w progu stanęto marzenie" (NKJP). Приводимые словосочетания обладают несомненными признаками метафоры.

После словосочетаний именного характера перейдем к еще одной их разновидности, в которой существенным становится действие.

Мечта, будучи движущей силой, заставляет ее обладателя действовать. Для подобного рода примеров характерной конструкцией будет мечта $+\mathrm{V}_{\text {inf }}$. Инфинитив при этом привносит с собой дополнительную информацию о том, на какое именно действие направлена мечта. Сказанное подтверждается довольно многочисленными словоупотреблениями, из которых приведем лишь такое: „У него есть мечта вылграть Лигу чемпионов (НКРЯг). В польском языке все это выглядит несколько более сложно. Идея реализации действия, сочетающегося с мечтой, воплощается в модель marzenie + aby/ żeby/ by $+\mathrm{V}_{\text {inf }} /$ part. praet. act. II. Например: „Spetniło się moje marzenie, aby studiować za granica; Bo to jest marzenie, żeby przekroczyć pewne granice; choć znat jej marzenie by być wysoka, wiotka i blada...; Gdyby został Pan autentycznie bogaty, to jakie marzenie by Pan zrealizowat?" (NKJP). Помимо этого, не слишком часто, используется также модель со знаком тире (marzenie $-\mathrm{V}_{\text {inf }}$ ), замещающим перечисленные союзы: „... mam tylko jedno marzenie — zdać do nastepnej klasy" (NKJP). Еще одна разновидность, выступающая относительно редко, имеет вид marzenie + gerundium:... „сzy śmiałkom uda się spetnić marzenie zdobycia najwyższej góry świata?”4. О формальной статистической устойчивости можно было бы говорить только на основании русскоязычного материала. В польском она растворяется в многообразии грамматических конструкций. Однако в обоих языках мечта семантически связывается с совершением какого-либо действия, и это можно признать существенным совпадением, хотя и далеко не ограничением.

Глагольные словосочетания могут также называть действие, производимое самой мечтой. В этой связи в существовании мечты можно выделить три основных проявления - начало, наличие и конец. Следуют они некоторым стандартным смыслам, выделяемым Е.Г. Борисовой (Борисова 1995: 22). Поскольку в разбираемых случаях мечта объявляет себя активно, выполняя функцию агенса, анализируемые словосочетания реализуются в составе глагольной модели $\mathrm{V}_{3 \mathrm{sg}}+$ мечта / marzenie // мечma / marzenie $+\mathrm{V}_{3 \mathrm{sg}}$.

${ }^{4}$ B NKJP такого примера не обнаружено, в то время как сходных примеров употребления достаточно много на веб-сайтах, см., напр.: www.telewizor.pl/opis/s_92_p_22319_.xhtml (доступ: 24.04.2016). 
Итак, первый, начальный, этап отмечает возникновение мечты, что обычно передается глаголом появиться (13): „Тогда у меня появилась меч$\boldsymbol{m a}$ - стать олимпийской чемпионкой” (НКРЯг); значительно реже глаголом родиться (4): „...на улице Клочковской в полуподвале рождалась и крепла мечта быть актрисой" (НКРЯг). Других глаголов, связываемых с появлением мечты, обнаружить не удалось. В польском материале обсуждаемый этап почти исчезает из поля зрения, ограничиваясь обычно только двумя словоупотреблениями глаголов: „Pod koniec szkoły pojawito sie marzenie o kontynuowaniu nauki w »normalnym « ogólniaku; ... zaczęło rodzić się marzenie o kraju własnym i sprawiedliwym" (NKJP). К перечисленным глаголам можно еще добавить powstać, budzić się, kiełkować (NKJP) ${ }^{5}$. Coxpaняя ту же семантику начала, они характеризуются единичной частотностью. Вместе с тем для обоих сопоставляемых языков можно отметить общее требование, идущее со стороны существительного и связываемое с использованием того, а не иного глагола. Данное обстоятельство позволяет осознавать более тесную связь между компонентами, выделенными жирным шрифтом, на фоне других сочетаний.

Следующий этап - это наличие, или существование, мечты, которой приписывается некая самостоятельность бытования, характерного как для безо́бразного употребления слова - существовать (5): „У человека сущеcтвует мечта - жить долго, а может и вечно" (НКРЯг), так и персонифицируемого - жить (3): „С тех пор та мечта живет во мне постоянно” (НКРЯг). В последнем случае в качестве места существования мечты часто указывается сердце. Если мечта приходит, то она остается на определенное время, что передается глаголами остаться, окрепнуть. Сопоставление с польскоязычным материалом показывает, что мечта есть и продолжается: jest (38), trwa (2), żyje, напр.: „Powszechne jest marzenie mężczyzn, by mieć kilka żon" (NKJP). Своим присутствием мечта создает также определенную поддержку, передаваемую посредством глаголов (nie) opuszczać, (nie) odstepować, towarzyszyć. хотя статистически и устойчивые, как представляется, черт семантической спаянности не обнаруживают. Если мечта существует, то она обычно сбывается, о чем говорится в таком выражении: „Jeśli twoje marzenie żyje, pewnego dnia się spetni"”.

Как уже говорилось, мечте приписывается свойство реализации, исполнения, как едва ли не основное и крайне важное для нее, производимое ею как бы без участия человека, что передается глаголами сбудется / cбывается / сбылась (174), осуществляется / осуществилась (32), исполнится / исполняется / исполнилась (20). Однако нередко при столкновении с дей-

\footnotetext{
5 В случае единичного употребления цифры в скобках не указываются.

${ }^{6}$ Их употребление подтверждается только поисковой системой google.pl

${ }^{7}$ https://girlsgenerationpoland.wordpress.com/czlonkinie/seohyun-maknae (доступ: 4.05.2016).
} 
ствительностью мечта теряет силу, переставая существовать. Два глагола, встретившиеся в составе соответствующих словосочетаний, предполагают распространение в существительном с предлогом, что находит свое отражение в модели мечта $+\mathrm{V}_{3 \mathrm{sg}}+\mathrm{B}_{\mathrm{Ac}}$ : мечта воплотилась в жсизнь (5) / превратилась в реальность (2). В польском материале подобное положение передается глаголами и глагольными сочетаниями spetni się / spelnia się / spetniło się (13); ziści się / ziścito się (8); urzeczywistniło się (6), zrealizowało się (5); przybrało realny ksztatt и т.п. (NKJP). Два первых из перечисленных следовало бы признать наиболее частотными, что позволяет говорить о коллокациях, близких отчасти к ФЕ.

Бывает и так, что по каким-то причинам мечта не сбывается. В этом случае она либо становится вечной, либо прекращает существование, забываясь и уходя в небытие. Достаточно привести такие примеры: мечта рух нула (3), ушла (2) (НКРЯг) ${ }^{8}$, закончилась ${ }^{9}$, исчезла $^{10}$, пропала $^{11}$, развеялась ${ }^{12}$. В польском материале не сбывшаяся мечта передается с помощью отрицания: marzenie nie ziścilo się (3), nie spelni się (3) (NKJP). Более решительный в своем выражении разрыв с мечтой выражается посредством глаголов skończyło sie (2), prysto (2), ginie (2), znika (NKJP). Оценивая семантическую спаянность компонентов, следовало бы сказать, что глаголы закончиться, исчезнуть, проnacmb, развеяться, польские skończyć się, prysnąć, zniknąć, ginąć в семантическом отношении достаточно широки, поэтому их сочетаемость с анализируемым существительным следует признать относительно свободной.

Подводя итоги, имеет смысл обратить внимание на следующие особенности:

1. Анализировавшиеся выражения представляют собой либо ФЕ, либо коллокации, в редких случаях свободные словосочетания. ФЕ при этом, с точки зрения их статистической устойчивости в настоящей работе не определявшиеся, в целом, как правило, довольно частотны, что является одним из критериев включения их в состав лексикографических источников. Коллокации, т.е. фразеологизированные выражения, обладают неодинаковой степенью семантической спаянности, определение которой, представляясь существенным, одновременно весьма затруднительно и интуитивно. Трудно вывести те критерии и показатели, которые можно бы было признать объективными и несомнительными. При всем том словосочетания, выделенные

${ }^{8}$ Если мечта уходит, то и должна приходить, однако подобного словосочетания в исследуемом материале Корпуса и веб-сайтов обнаружить не удалось.

9 www.lookatme.ru/flow/dizayn/reklamnyie-fotografyi/66640-elisabeth-hof (доступ: 24.04.2016).

10 www.goroddosug.ru/sport/euro_2012/articles/5952 (доступ: 24.04.2016).

$11 \mathrm{http} / / /$ wap.sovsport.ru/gazeta/article-item/882695 (доступ: 24.04.2016).

$12 \mathrm{https} / / /$ otvet.mail.ru/question/28210184 (доступ: 24.04.2016). 
в тексте жирным шрифтом, можно с определенной дозой вероятности признать коллокациями.

2. Обсуждавшаяся лексическая единица (мечта / marzenie) в исходной форме обладает значительно бо́льшими возможностями сочетания с другими словами, чем первоначально казалось. Об этом свидетельствуют словоупотребления в текстах обоих корпусов. Тем не менее, статистические данные не разрешают вопроса оценки семантической спаянности компонентов исследуемых выражений, а иногда эту картину и затемняют.

3. В случае несовпадения данных корпусов с данными поисковой системы Google еще труднее решить проблему совмещения семантической близости компонентов с их статистической устойчивостью, а тем самым, воспроизводимостью. Иными словами, статистическая устойчивость непосредственного влияния на образование коллокаций не оказывает.

4. Статистически устойчивые словосочетания показательны, в первую очередь, с точки зрения их речевого употребления и, что из этого следует, могут использоваться для дидактических целей, при выработке навыков овладения языком. В связи с чем они должны занимать особое место в процессе преподавания и обучения, предоставляя существующий в языке материал в виде конструкций и способов характерного для него выражения мыслей, независимо от того ФЕ это, коллокация или свободное сочетание.

5. Механизм выбора сочетаемостной пары, так же, как и регулярность и повторяемость компонентов состава того или иного словосочетания, нередко не поддаются ясному объяснению, определяясь особенностями языкового и речевого использования, т.е. причинами узуальными.

\section{Библиография}

\section{Источники}

\begin{tabular}{|c|c|}
\hline KJP & J̨̧ \\
\hline DS & $\begin{array}{l}\text { Stownik dobrego stylu czyli wyrazy, które się lubia, red. M. Bańko, Warszawa: } \\
\text { PWN, } 2007 .\end{array}$ \\
\hline FJP & $\begin{array}{l}\text { - Stownik frazeologiczny jezzyka polskiego, S. Skorupka, t. 1, Warszawa: Wiedza Po- } \\
\text { wszechna, } 1989 .\end{array}$ \\
\hline FV & — Stownik frazeologiczny, oprac. A. Kłosińska et al., Warszawa: PWN, 2005. \\
\hline SF & $\begin{array}{l}\text { - Wielki stownik frazeologiczny polsko-rosyjski i rosyjsko-polski, red. J. Lukszyn, } \\
\text { Warszawa: Harald G Dictionaries, } 1998 .\end{array}$ \\
\hline SJP & — Wielki słownik języka polskiego, wsjp.pl. \\
\hline КРЯг & $\begin{array}{l}\text { - Национальный корпус русского языка, www.ruscorpora.ru (газетный подко- } \\
\text { рпус). }\end{array}$ \\
\hline Ш & $\begin{array}{l}\text { - Толковый словарь русского языка, ред. С.И. Ожегов, Н.Ю. Шведова. Москва: } \\
\text { Азбуковник, } 1997 .\end{array}$ \\
\hline
\end{tabular}


СРФ——ловарь русской фразеологии. Историко-этимологический справочник, А.К. Бирих, В.М. Мокиенко, Л.И. Степанова, Санкт-Петербург: Фолио-Пресс, 1999.

УСС - Учебный словарь сочетаемости слов русского языка, ред. В.В. Морковкин, П.Н. Денисов, Москва: Русский язык, 1978.

\section{Литература}

Борисова Е.Г., 1995, Коллокаиии. Что это такое и как их изучать, Москва: Филология.

Влавацкая М.В., 2011, Система базовых понятий комбинаторной лингвистики, «Мир науки, культуры, образования», № 1, с. 32-38, http://cyberleninka.ru/article/n/sistema-bazovyh-ponyatiy-kombinatornoy-lingvistiki-1.

Жеребило Т.В., 2010, Словарь лингвистических терминов. Назрань, http://lingvistics_dictionary.academic.ru.

Захаров В.П., Хохлова В.М., 2010, Анализ эффективности статистических методов выявления коллокачий в текстах на русском языке. http://www.dialog-21.ru/digests/dia$\log 2010 /$ materials/pdf/22.pdf.

Иванова А.А., 2011, Этнокультурная спеиифика понимания константы 'мечта'в английской и франиузской языковой картине мира, Вестник Челябинского ГУ, Выпуск № 10, с. 60-62, http:/cyberleninka.ru/article/n/etnokulturnaya-spetsifika-ponimaniya-konstanty-mechta-vangliyskoy-i-frantsuzskoy-yazykovoy-kartine-mira.

Никифорова Е.Б., 2006, Смысловая эволючия концепта «мечта» и его вербализащия в русском языке (XIX-XXI вв.), Вестник СамГУ, Выпуск 10-2, с. 204-210, http://cyberleninka.ru/ article/n/smyslovaya-evolyutsiya-kontsepta-mechta-i-ego-verbalizatsiya-v-russkom-yazyke-xix-xxi-vv.

Сергеев С.А., 2005, Особенности объективации концепта «мечта» в русской языковой картине мира, АКД, Кемерово, www.dslib.net.

Сергеев С.А., 2006, Понятийная составляющая признаковой структуры концепта мечта, «Политическая лингвистика», № 17, с. 207-214, http://cyberleninka.ru/article/n/ponyatiynaya-sostavlyayuschaya-priznakovoy-struktury-kontsepta-mechta.

\section{Meчma / marzenie (dream) like a collocation component in current Russian and Polish usage}

\section{Summary}

The article is devoted to the problems of words connectivity мечma and marzenie in Russian and Polish common and traditional usage.

The analyzed expressions are fixed in lexicographical tradition but also characterized in reproduced forms and relative high frequency in the contexts coming from the selected languages corpus. These expressions defined as statically fixed present strong semantic connections that allows to treat them similarly to phraseological units. Expressions characterized with a weaker degree of connections between their components are collocations or close to free word groups.

The study does not support the thesis that high frequency favors creation of stable connections. High frequency can be observed not only in phraseological units and collocations but also in commonly used free word groups.

Keywords: dream, phraseology, collocations, Russian, Polish, usage 


\section{Meчma / marzenie jako komponent kolokacji w praktyce użytkowników języka rosyjskiego i polskiego}

Streszczenie

W artykule przedstawiono problemy łączliwości leksemów мeчma i marzenie w związkach wyrazowych używanych w języku rosyjskim i polskim. Zbadano wyrażenia rejestrowane w słownikach, lecz także inne połączenia, charakteryzujące się odtwarzalnością i stosunkowo wysoką frekwencją w tekstach korpusów obu języków. Wyrażenia te, określane jako statystycznie stałe, wykazują czasami cechy silniejszego semantycznego zespolenia, co pozwala traktować je jako jednostki bliższe frazeologizmom. Połączenia charakteryzujące się słabszym stopniem zespolenia komponentów pozostają kolokacjami lub zbliżają się do związków luźnych.

Przeprowadzone badania nie potwierdzają jednak tezy, że wysoka frekwencja sprzyja powstawaniu związków stałych, albowiem wysoką częstotliwość mogą wykazywać zarówno jednostki frazeologiczne, jak i kolokacje oraz związki luźne.

Słowa kluczowe: marzenie, frazeologizmy, kolokacje, język polski, język rosyjski 